\title{
PENGARUH LOCUS OF CONTROL DAN KEPRIBADIAN (PERSONALITY) TERHADAP KEINGINAN UNTUK BERTINDAK (INTENTION TO ACT) SISWA
}

\author{
Devie Amalia Lestari ${ }^{1}$, I Made Putrawan ${ }^{2}$, Diana Vivanti Sigit ${ }^{3}$ \\ ${ }^{1}$ Student of Biology Education Departement of State University of Jakarta \\ ${ }^{2}$ Environmental Education Departement of State University of Jakarta \\ ${ }^{3}$ Biology Education Departement of State University of Jakarta
}

Email: devieamalial@gmail.com,putrawan.imade@yahoo.com,dianavivanti@yahoo.com

\begin{abstract}
Environmental problems cause threats to the environment, such as global warming, urban air pollution, clean water crises, environmental noise and loss of biodiversity. This problem is caused by human behavior. Resolution of environmental problems can be done by community or private components, one component of community is students. The effort that can be done is to increase intention to act on the environment. This study aims to determine the effect of locus of control and personality on students' intention to act. Research conducted at SMA Negeri 31 Jakarta on the Semester I of the 2019/2020 school year. The method used is the survey with quantitative-causal causal approach and path analysis. The samples used were 99 students of class XI IPA. The reliability coefficient of Locus of control $\left(X_{1}\right)$ is 0.680, Personality $\left(X_{2}\right)$ is 0.759, and Intention to Act $\left(X_{3}\right)$ is 0.878. Based on the results, it can be concluded that personality is not good as a mediator variable between the locus of control and intention to act.
\end{abstract}

Keywords: Students, locus of control, personality, intention to act, path analysis 


\section{PENDAHULUAN}

Kerusakan lingkungan hidup di dunia pada umumnya dan Indonesia pada khususnya menjadi salah satu topik perdebatan yang hangat dalam berbagai kesempatan di berbagai belahan dunia. Disepakati secara luas bahwa perilaku manusia saat ini memiliki dampak yang merugikan pada lingkungan planet ini (IPCC, 2014). Berbagai masalah lingkungan menimbulkan ancaman bagi lingkungan di antaranya pemanasan global, pencemaran udara perkotaan, kekurangan air, kebisingan lingkungan dan hilangnya keanekaragaman hayati. Intergovernmental Science-Policy Platform on Biodiversity and Ecosystem Services (IBES) memperingatkan bahwa 1 juta spesies dalam resiko kepunahan yang bisa terjadi kapan pun dalam sejarah manusia (Greenpeace Indonesia, 2019). Masalah ini berakar pada perilaku manusia dan dapat dikelola dengan mengubah perilaku yang relevan sehingga dapat mengurangi dampak lingkungannya (Steg \& Vlek, 2009).

Perilaku manusia berhubungan dengan lingkungan hidup. Salah satu hubungan antara penurunan kualitas lingkungan hidup dan manusia (sosial) yaitu sebagian besar penurunan kualitas lingkungan hidup hasil dari tindakan atau perilaku manusia (Barry, 2007). Kepribadian manusia itu sendiri dan keadaan lingkungan sekitar akan mempengaruhi perilaku lingkungan seseorang (Laurens, 2012). Penyelesaian masalah terhadap lingkungan dapat dilakukan oleh komponen masyarakat maupun pribadi. Salah satu upaya yang dapat dilakukan untuk penyelesaian masalah yaitu dengan menumbuhkan keinginan untuk peduli terhadap lingkungan yang berdampak terhadap perilaku seseorang. Hal tersebut dapat dilakukan pada salah satu komponen masyarakat yaitu siswa melalui pendidikan di sekolah.

Permasalahan lingkungan yang terjadi dapat dipecahkan dengan keinginan bertindak siswa atau intention to act siswa terhadap lingkungan. Siswa yang memiliki keinginan bertindak terhadap lingkungan akan menumbuhkan rasa peduli terhadap lingkungan. Intention to Act adalah keinginan siswa untuk melakukan perilaku terhadap lingkungan sehingga dapat memperkirakan dampak terhadap lingkungan. 
Menurut Ferraz (2017) intention atau intensi didefinisikan sebagai rencana sadar seseorang untuk melakukan perilaku tertentu atau bahkan sebagai penilaian tentang perilakunya. Intention diperkenalkan sebagai komponen mediator antara sikap dan perilaku, yaitu sikap melayani untuk mengarahkan intention sejauh mana seseorang akan bersedia melakukan sesuatu. Sedangkan menurut Patricia (2012), Intention didefinisikan sebagai persepsi subjektif seseorang dan laporan tentang probabilitas bahwa dia akan melakukan perilaku yang dimaksud persepsi seseorang terhadap tekanan social membuatnya melakukan atau tidak melakukan perilaku oleh orang, kelompok, atau hal yang dia pedulikan. Menurut Putrawan (2014) bahwa keinginan (niat) untuk bertindak atau intention to act merupakan dasar untuk tumbuhnya perilaku bertanggung jawab terhadap lingkungan hidup. Hines, dkk (2010) mengembangkan model perilaku bertanggung jawab lingkungan. Dalam model tersebut, keinginan untuk peduli terhadap lingkungan salah satunya dipengaruhi oleh faktor kepribadian yaitu attitude, locus of control dan personal responsibility.

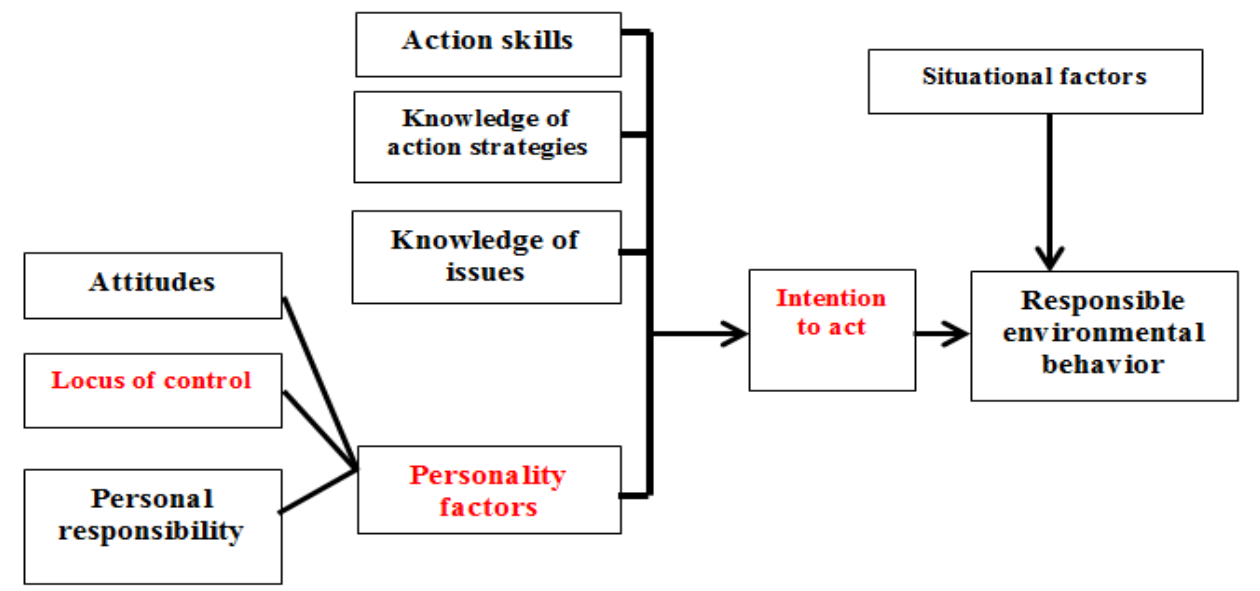

Gambar 1. The Model of Responsible Environmental Behavior (Hines, Hungerford \& Tomera, 2010)

Locus of Control adalah karakteristik atau sifat seseorang dalam interaksinya dengan orang lain yang berkaitan dengan keberhasilan atau kegagalan seseorang dalam menjalani hidup dan apabila keberhasilan dan kegagalan tersebut dianggap 
disebabkan oleh diri sendiri maka locus of control nya internal, sebaliknya disebut eksternal. Menurut Colquitt, Lepinne dan Wesson (2011) locus of control adalah mencerminkan apakah suatu peristiwa itu disebabkan oleh orang itu sendiri atau lingkungan luar. Orang yang cenderung memiliki locus of control eksternal, berarti bahwa mereka sering percaya peristiwa yang terjadi di sekitar didorong oleh keberuntungan, kebetulan atau takdir. Sedangkan orang yang cenderung memiliki locus of control internal berarti bahwa mereka percaya keberuntungan karena perilaku sendiri.

Faktor lain dalam meningkatkan keinginan bertindak siswa adalah kepribadian atau personality. Personality adalah adalah sifat atau karakteristik yang dimiliki siswa dalam berinteraksi dengan individu lain atau lingkungannya. McCrae dan Costa mengukur Big Five Personality dengan kuisioner NEO-Personality Inventory Revised seperti Tabel 1. berikut:

Tabel 1. Lima model kepribadian Costa dan McCrae (2009)

\begin{tabular}{ll}
\hline Dimensi & Ciri-Ciri \\
\hline Openness $(O)$ & Fantasy, Aesthetics, Feelings, Action, Ideas, Values. \\
Conscientiousness $(C)$ & $\begin{array}{l}\text { Competence, Order, Dutifulness, Achievement } \\
\text { Stiriving, Self-Discipline, Deliberation. }\end{array}$ \\
Extraversion $(E)$ & $\begin{array}{l}\text { Trust, Straight Forwardness, Altruism, Compliance, } \\
\text { Modesty, Tender-Mindedness. }\end{array}$ \\
Agreeableness $(A)$ & $\begin{array}{l}\text { Warmth, Gregariousness, Assertiveness, Activity, } \\
\text { Excitement-Seeking, Positive Emotions. }\end{array}$ \\
& $\begin{array}{l}\text { Anxiety, Angry Hostility, Depression, Self- } \\
\text { Consciousness, Impulsiveness, Vulnerability }\end{array}$
\end{tabular}

Terdapat lima dimensi personality yaitu Openness (keterbukaan), Conscientiousness (ketelitian), Extraversion (pandai bergaul), Agreeableness (kesepakatan) dan Neuroticism (kestabilan emosi). Kepribadian siswa cenderung 
beragam, hal ini yang mengakibatkan keinginan bertindak siswa pun akan beragam terhadap lingkungan.

Berdasarkan uraian diatas, maka rumusan masalah pada penelitian ini adalah: 1) Apakah Locus of Control berpengaruh langsung terhadap Personality siswa?; 2) Apakah Personality berpengaruh langsung terhadap Intention to Act siswa?; 3) Apakah Locus of Control berpengaruh langsung terhadap Intention to Act siswa?; 4) Apakah Locus of Control berpengaruh tidak langsung terhadap Intention to Act melalui Personality siswa?. Penelitian ini bertujuan untuk mengetahui pengaruh locus of control dan personality terhadap intention to act siswa.

\section{METODOLOGI}

Model dari penelitian ini dapat digambarkan sebagai berikut:

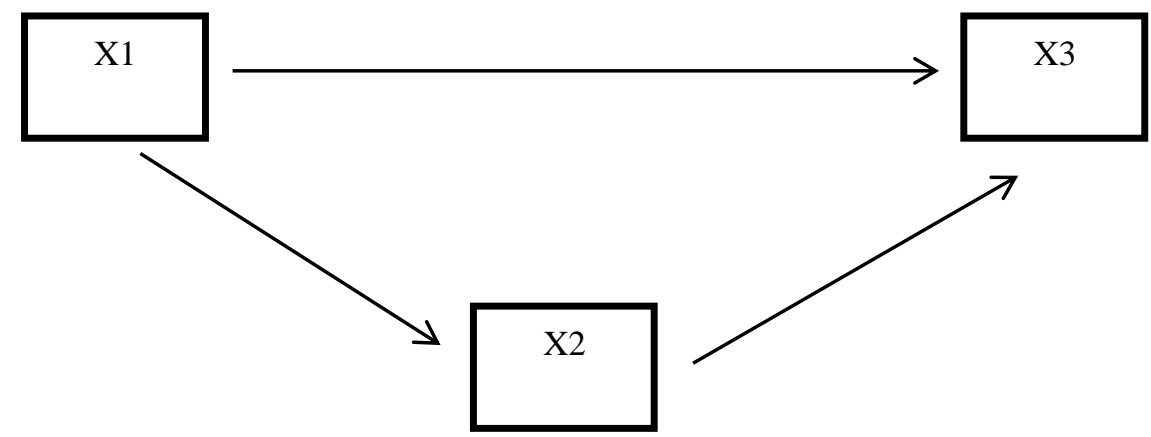

Gambar 2. Model Hipotetik

Keterangan

$\mathrm{X}_{1}$ : Locus of Control

$\mathrm{X}_{2}:$ Personality

$\mathrm{X}_{3}$ : Intention to Act

Metode penelitian yang digunakan adalah metode survei yang bersifat kausal. Penelitian ini termasuk kedalam jenis penelitian kuantitatif dengan menggunakan analisis jalur (path analysis) yang dipilih untuk menganalisis pola hubungan antar variabel dengan tujuan untuk mengetahui pengaruh secara langsung maupun tidak langsung antara variabel eksogen dan endogen. Penelitian ini 
mempunyai tiga variabel, yaitu $\mathrm{X}_{1}$ (Locus of Control) dan $\mathrm{X}_{2}$ (Personality) sebagai variabel eksogen serta $\mathrm{X}_{3}$ (Intention to Act) sebagai variabel endogen.

Pemilihan sampel dan populasi dilakukan dengan teknik pemilihan sampel bertingkat (multi-stage random sampling) dengan tahapan sebagai berikut: Pertama, pemilihan populasi penelitian yang akan diteliti adalah seluruh siswa SMA Negeri kelas XI IPA di Jakarta; Kedua, dari seluruh siswa SMA Negeri kelas XI IPA di Jakarta, terpilihlah SMA Negeri di Jakarta Timur dengan teknik Purposive Sampling; Ketiga, dari seluruh kecamatan yang terdapat di Jakarta Timur, terpilihlah kecamatan Matraman dengan teknik Cluster Random Sampling; Keempat, dari seluruh SMA Negeri yang ada di Kecamatan Matraman terpilih SMA Negeri 31 Jakarta dengan menggunakan Cluster Random Sampling; Kelima, dari seluruh siswa kelas XI IPA dipilih tiga kelas dengan total 101 siswa sebagai responden; Keenam, dari 101 siswa, ditentukan 99 sebagai sampel dengan Simple Random Sampling. Pengumpulan data untuk mengetahui locus of control, personality, dan intention to act siswa dilakukan dengan menyebarkan instrumen berupa opinioner.

\section{HASIL DAN PEMBAHASAN}

Pada hipotesis pertama Locus of Control $\left(\mathrm{X}_{1}\right)$ terhadap Personality $\left(\mathrm{X}_{2}\right)$ hasil perhitungan menggunakan uji signifikansi, uji linieritas dan uji koefisien jalur untuk penyusunan model persamaan regresi, diperoleh konstanta regresi $\mathrm{a}=34.639$ dan koefisien regresi $b=1.172$. Dengan demikian model persamaan regresi sederhana yang terbentuk $\hat{\mathrm{X}}_{2}=34.639+1.172 \mathrm{X}_{1}$. Kemudian untuk mengetahui pengaruh langsung Locus of Control $\left(\mathrm{X}_{1}\right)$ terhadap Personality $\left(\mathrm{X}_{2}\right)$ dilakukan perhitungan koefisien jalur. Hasil perhitungan dapat dilihat pada tabel 2. sebagai berikut: 
Tabel 2. Koefisien Jalur Locus of Control $\left(\mathrm{X}_{1}\right)$ terhadap Personality $\left(\mathrm{X}_{2}\right)$

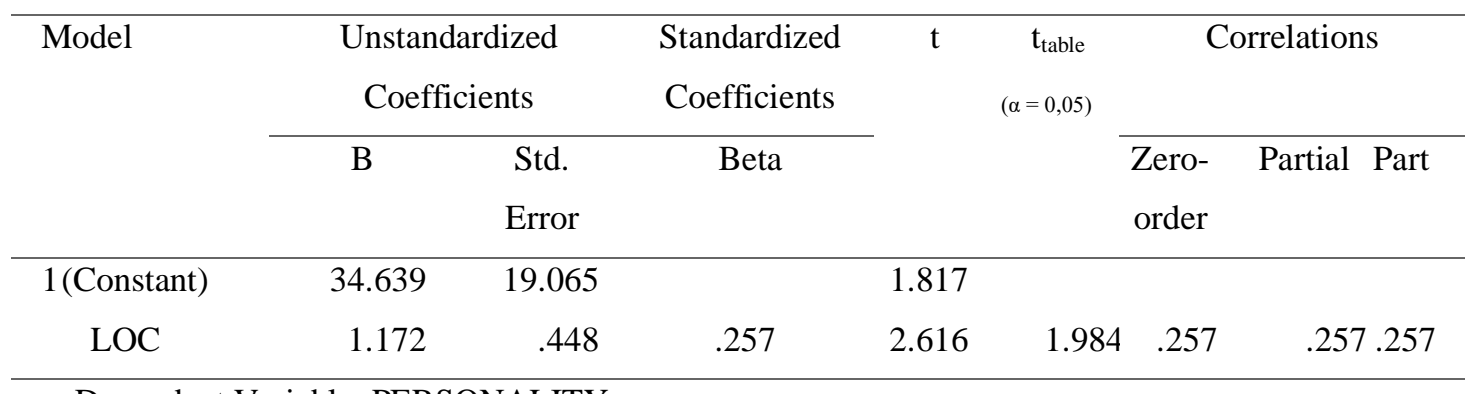

a. Dependent Variable: PERSONALITY

Hasil perhitungan path analysis koefisien jalur $\left(\mathrm{Phi}_{21}\right)$ sebesar 0.257 , dengan $\mathrm{t}_{\text {hitung }}=$ $2.616>\mathrm{t}_{\text {tabel }(0.05 ; 97)}=1.984$, yang artinya terdapat pengaruh langsung antara Locus of Control dan Personality yang signifikan. Pada hipotesis kedua Personality $\left(\mathrm{X}_{2}\right)$ terhadap Intention to Act $\left(\mathrm{X}_{3}\right)$ hasil perhitungan menggunakan uji signifikansi, uji linieritas dan uji koefisien jalur untuk penyusunan model persamaan regresi, diperoleh konstanta regresi $\mathrm{a}=36.561$ dan koefisien regresi $\mathrm{b}=0.709$. Dengan demikian model persamaan regresi sederhana yang terbentuk $\hat{X} 3=36.561+0.709$ $\mathrm{X}_{2}$. Kemudian untuk mengetahui pengaruh langsung Personality $\left(\mathrm{X}_{2}\right)$ terhadap Intention to Act $\left(\mathrm{X}_{3}\right)$ dilakukan perhitungan koefisien jalur. Hasil perhitungan dapat dilihat pada tabel 3. sebagai berikut:

Tabel 3. Koefisien Jalur Personality $\left(\mathrm{X}_{2}\right)$ terhadap Intention to Act $\left(\mathrm{X}_{3}\right)$

\begin{tabular}{|c|c|c|c|c|c|c|c|c|}
\hline \multirow[t]{4}{*}{ Model } & \multirow{2}{*}{\multicolumn{2}{|c|}{$\begin{array}{l}\text { Unstandardized } \\
\text { Coefficients }\end{array}$}} & \multirow{4}{*}{$\begin{array}{c}\begin{array}{c}\text { Standardized } \\
\text { Coefficients }\end{array} \\
\text { Beta }\end{array}$} & \multirow[t]{4}{*}{$\mathrm{T}$} & \multirow{4}{*}{$\begin{array}{l}\mathrm{t}_{\text {table }} \\
(\alpha=0.05)\end{array}$} & \multicolumn{3}{|c|}{ Correlations } \\
\hline & & & & & & & & \\
\hline & B & Std. & & & & Zero- & Partial & Part \\
\hline & & Error & & & & order & & \\
\hline 1 (Constant) & 36.561 & 7.435 & & 4.918 & & & & \\
\hline PERSON & .709 & .087 & .636 & 8.114 & 1.984 & .636 & .636 & .636 \\
\hline ALITY & & & & & & & & \\
\hline
\end{tabular}

a. Dependent Variable: ITA

Hasil perhitungan path analysis koefisien jalur $\left(\mathrm{Phi}_{32}\right)$ sebesar 0.636 dengan $\mathrm{t}_{\text {hitung }}=$ $8.114>\mathrm{t}_{\text {tabel }(0.05 ; 97)}=1.984$, yang artinya terdapat pengaruh langsung antara Personality terhadap Intention to Act yang signifikan. 
Pada hipotesis ketiga, diperoleh konstanta regresi $\mathrm{a}=54.731$ dan koefisien regresi $\mathrm{b}$ $=0.982$. Dengan demikian model persamaan regresi sederhana yang terbentuk $\hat{\mathrm{X}} 3=$ $54.731+0.982 \mathrm{X}_{1}$. Uji signifikansi persamaan regresi didapatkan hasil yang tidak signifikan pada jalur Locus of Control $\left(\mathrm{X}_{1}\right)$ terhadap Intention to Act $\left(\mathrm{X}_{3}\right)$, sehingga tidak dilakukan pengujian hipotesis. Pada hipotesis keempat, untuk mengetahui pengaruh tidak langsung Locus of Control $\left(\mathrm{X}_{1}\right)$ terhadap Intention to Act $\left(\mathrm{X}_{3}\right)$ melalui Personality $\left(\mathrm{X}_{2}\right)$ perlu diketahui koefisien jalur antara $\mathrm{X}_{1}$ terhadap $\mathrm{X}_{2}$ dan $\mathrm{X}_{2}$ terhadap $\mathrm{X}_{3}$ yaitu sebesar 0.257 dan 0.636, sehingga diperoleh Phi 31.2 sebesar 0.163, dengan menggunakan uji-t parsial maka $\mathrm{t}_{\text {hitung }}=1.617<\mathrm{t}_{\text {tabel }}(0.05 ; 96)=1.984$ yang berarti tidak terdapat pengaruh tidak langsung $X_{1}$ terhadap $X_{3}$ melalui $X_{2}$. Dengan demikian dapat disimpulkan bahwa personality tidak bisa sebagai mediator locus of control terhadap intention to act siswa.

Tabel 4. Rangkuman Hasil Pengujian Hipotesis

\begin{tabular}{rccc}
\hline Hipotesis Statistika & Koefisien Jalur & $\mathrm{t}_{\text {hitung }}$ & $\mathrm{t}_{\text {tabel }}$ \\
\hline H0 $:$ Phi21 $=0$ & 0.257 & 2.616 & $1.984_{(0.05 ; 97)}$ \\
H1 : Phi21 $>0$ & & & \\
H0 : Phi32 $=0$ & 0.636 & 8.114 & $1.984_{(0.05 ; 97)}$ \\
H1 $:$ Phi32 $>0$ & - & - & - \\
H0 : Phi31 $=0$ & & & $1.984_{(0.05 ; 96)}$ \\
H1 : Phi31 $>0$ & 0.163 & 1.617 & \\
H0 $:$ Phi31.2 $=0$ & & & \\
H1 : Phi31.2 $>0$ & & & \\
\hline
\end{tabular}

Berdasarkan hasil pengujian hipotesis pertama menunjukkan bahwa terdapat pengaruh langsung locus of control terhadap personality yang signifikan. Hasil ini sesuai dengan model penelitian dari Hines yang menyatakan bahwa terdapat hubungan positif antara locus of control dengan personality. Menurut Weimer, Ahlstrom, Lisspers \& Lipsanen (2017) siswa dengan locus of control internal percaya dapat mengendalikan peristiwa kehidupan karena perilakunya 
ditentukan oleh faktor internal seperti kerja keras, pengambilan keputusan, keterampilan pemecahan masalah, upaya, dan persuasi.

Berdasarkan hasil pengujian hipotesis kedua menunjukkan bahwa terdapat pengaruh langsung personality terhadap intention to act yang signifikan. Hasil ini sesuai dengan model penelitian Hines yang menyatakan bahwa dalam melakukan suatu tindakan seseorang mengacu pada kepribadiannya. Hasil ini relevan dengan penelitian Riska Dian Pratiwi (2019) yang mengemukakan bahwa kepribadian positif siswa menunjukkan kecenderungan siswa untuk bertindak positif terhadap lingkungan dengan lebih baik. Hasil penelitian Yu dan Yu (2017) juga menyatakan bahwa kepribadian memiliki pengaruh positif pada kesediaan seseorang untuk bertindak terhadap lingkungan. Lalu Meier (2012) menegaskan yaitu ciri-ciri kepribadian yang cenderung sebagai satu dimensi dari perbedaan individu, yang mempengaruhi keinginan dan perilaku. Berdasarkan temuan Robbins (2001) orang yang memiliki skor personality tinggi cenderung mendengarkan kata hati dan mengejar sedikit tujuan dalam satu cara yang terarah dan cenderung bertanggung jawab, kuat bertahan dan berorientasi pada prestasi. Sementara yang skornya rendah akan cenderung menjadi lebih kacau pikirannya, mengejar banyak tujuan, dan lebih hedonistik. Siswa di sekolah memiliki kepribadian yang berbeda-beda berdasarkan 5 dimensi kepribadian, kepribadian tersebut berpengaruh terhadap keinginan siswa dalam bertindak.

Hasil pengujian hipotesis ketiga tidak dilakukan. Sehingga pada penelitian ini locus of control tidak berpengaruh langsung terhadap intention to act. Hal ini sesuai dengan penelitian Hines tetapi tidak relevan dengan penelitian Hwang, Kim \& Jeng (2010) yang menemukan terdapat pengaruh locus of control terhadap intention. Ditegaskan bahwa jika pendidik ingin mengubah atau meningkatkan niat untuk bertindak, akan efektif untuk menggunakan program dan bahan yang dapat merangsang locus of control internal. Serta temuan Yang, Lin \& Liu (2016) yang menunjukkan terdapat hubungan signifikan antara locus of control dan intention, bahwa siswa dengan locus of control internal mampu mengontrol yang terjadi dan memiliki intention sehingga siswa memiliki perilaku peduli lingkungan terhadap norma-norma dan nilai-nilai yang ada di lingkungan lebih tinggi. Menurut Yu dan 
Yu (2017), kepedulian lingkungan atau environmental concern dapat mempengaruhi sikap pro lingkungan (pro-environmental attitude) begitu pula dengan nilai lingkungan (sustainability value). Kemudian sikap pro lingkungan akan menimbulkan keinginan seseorang untuk berperilaku (intention to act). Berdasarkan hasil penelitian sebelumnya, intention to act memiliki hubungan dengan environmental concern, sehingga seseorang yang memiliki intention to act tidak perlu memiliki locus of control internal.

Dalam penelitian Putrawan (2016) digambarkan bahwa terdapat hubungan pengetahuan dengan intention to act dalam berperilaku terhadap lingkungan, jika manusia memahami bahkan lebih sadar akan lingkungan, mereka akan termotivasi untuk lebih responsif terhadap lingkungan. Banyaknya faktor yang mempengaruhi intention to act siswa menunjukkan bahwa keinginan bertindak siswa dapat tumbuh walaupun siswa memiliki locus of control eksternal. Sehubungan dengan teori generasi: (1) generasi Baby Boomer, lahir tahun 1946-1964, (2) generasi X, lahir tahun 1965 - 1980, (3) generasi Y, lahir pada 1981-1994, (4) Generasi Z, lahir pada 1995-2010, dan (5) Generasi Alpha, lahir 2011-2025 (Tapscott, 2009). Karakteristik generasi ini adalah ketergantungan dengan tampilan layar dan dunia layar sentuh (McCrindle, 2015). Generasi berusia 15-24 tahun lebih menyukai topik pembicaraan yang terkait musik/film, olahraga, dan teknologi (Alvara Research Center, 2014). Dapat dikatakan siswa memiliki minat baca yang rendah mengenai politik sehingga siswa tidak memiliki locus of control eksternal mengenai permasalahan lingkungan terhadap pemerintah. Siswa yang memiliki locus of control internal maupun locus of control eksternal tidak mempengaruhi intention to act siswa dan dalam penelitian ini intention to act siswa tumbuh karena faktor lain.

Berdasarkan hasil pengujian hipotesis keempat menunjukkan bahwa terdapat pengaruh tidak langsung locus of terhadap intention to act melalui personality secara tidak signifikan. Hasil penelitian ini tidak sesuai dengan model Hines, dalam model tersebut, keinginan untuk peduli terhadap lingkungan salah satunya dipengaruhi oleh faktor kepribadian yaitu attitude, locus of control dan personal responsibility. Meskipun demikian, menurut Ajzen (2011) dalam Theory of Planned Behavior menyatakan bahwa intention to act dipengaruhi oleh faktor - 
faktor seperti attitude, norma subjektif (subjective norms) dan kontrol perilaku (perceived behavioral control) sehingga suatu niat dalam berperilaku (intention) akan sangat berpengaruh terhadap perilaku yang digunakan dalam kehidupan. Banyaknya faktor yang dapat mempengaruhi intention to act, sehingga dalam penelitian ini personality tidak baik dijadikan sebagai variabel mediator locus of control terhadap intention to act.

\section{KESIMPULAN}

Beberapa temuan dalam penelitian ini sebagai berikut: 1) Locus of Control berpengaruh langsung terhadap Personality siswa secara signifikan; 2) Personality berpengaruh langsung terhadap Intention to Act siswa secara signifikan; 3) Locus of Control tidak berpengaruh langsung terhadap Intention to Act siswa; dan 4) Locus of Control berpengaruh tidak langsung terhadap Intention to Act siswa melalui Personality secara tidak signifikan.

Berdasarkan temuan-temuan tersebut dapat disimpulkan bahwa untuk mengurangi variasi intention to act siswa dapat mempertimbangkan variasi dari faktor personality agar dapat meminimalkannya. Siswa memiliki intention to act sesuai dengan personality yang dimiliki siswa. Selain itu terdapat pengaruh tidak langsung locus of control terhadap intention to act melalui personality secara tidak signifikan, sehingga personality tidak baik menjadi variabel mediator yang menengahi locus of control terhadap intention to act siswa dalam penelitian ini.

\section{DAFTAR PUSTAKA}

Alvara Research Centre. (2014). Generasi Millennial Indonesia: Tantangan dan Peluang Pemuda Indonesia

Barry, John. (2007). Environment and Social Theory. London: Routledge.

Colquitt, Jason A., Jeffery A. LePine, and Michael J. (2011). Wesson. Organizational Behavior. New York: McGraw-Hill. 
Ferraz, S. B., Buhamra, C, Laroche, M., \& Veloso, A. R. (2017). Green Products: A cross-cultural study of attitude, intention and purchase behavior. RAM. Revista de Administração Mackenzie, 18 (5), 12 - 38.

Fishbein, M., \& Ajzen, I. (2011). Predicting and Changing Behavior. New York: Psychology Press

Greenpeace Indonesia. (2019). Hilangnya Keanekaragaman Hayati: Kebutuhan Mendesak Melindungi Hutan dan Laut serta Perubahan Pola Makan. Jakarta: Greenpeace.

Hwang, Y. H., Kim, S. I., \& Jeng, J. M. (2010). Examining the Causal Relationships Among Selected Antecedents of Responsible Environmental Behavior. The Journal of Environmental Education, 31(4), 19-25. https://doi.org/10.1080/00958960009598647

Hines, J. M., Hungerford, H. R., \& Tomera, A. N. (2010). Analysis and synthesisof research on responsible environmental behavior: A meta-analysis. The Journal of Environmental Education, 18, (2), 1-8. doi: https: //doi.org/10.1080/00958964.1987.9943482

IPCC. (2014). Summary for Policymakers. Climate Change 2014: Synthesis Report. Contribution of Working Groups I, II and III to the Fifth Assessment Report of the Intergovernmental Panel on Climate Change. https://doi.org/10.1017/CBO9781107415324

Laurens, J.M. (2012). Changing Behavior and Environment in a Community-Based Program of the Riverside Community, Procedia-Social and Behavioral Sciences, 36: 372-382.

McCrae, R. R., Costa, P. T. Jr. (2009). The Five-Factor Model of personality traits: consensus and controversy. In P. L. Corr and G. Matthews (eds.). Cambridge: Cambridge University Press.

McCrindle, M. (2015). The ABC of XYZ: Understanding the Global Generations. Australia: UNSW Press.

Meier B. P., Moeller S. K., Riemer-Peltz M., \& Robinson M. D. (2012). Sweett Taste Preference and Experiences Predict Prosocial Inferences, Personalities, and Behaviors. Journal of Personality and Social Psychology, 102(1), pp. 163174. https://doi.org/10.1037/a0025253.

Patricia, Arttachariya. (2012) Environmentalism and Green Purchasing Behavior. Assumtiom University Thailand.Variabel Distinction in Social Psychological Research: Conceptual, Strategic, and Statistical Considerations. Journal of Personality and Social Psychology. 51 (6), pp: 1173-1182. 
Pratiwi, Riska D., Rusdi, \& Komala, Ratna. (2019). The effects of personality and intention to act toward responsible environmental behavior. Jurnal Pendidikan Biologi Indonesia, 5(1), p.169-176. https://doi.org/10.22219/pjbi.v5i1.7120

Putrawan, I Made. (2014). Konsep-Konsep Dasar Ekologi Dalam Berbagai Aktivitas Lingkungan. Bandung: Alfabeta.

Putrawan, I. Made, Diana V. Sigit, Angela M. (2016). Pengaruh Kepribadian (Ekstrovert VS Introvert) Terhadap Water Footprint Siswa Sekolah Menengah Atas di Jakarta, BIOSFER: Jurnal Pendidikan Biologi 9(1), pp. 1-9.

Robbins, S.P. (2001). Perilaku Organisasi : konsep, kontroversi, aplikasi. Versi Bahasa Indonesia. Jakarta : Prehallindo.

Steg, L. \& Vlek, C. (2009). Encouraging pro-environmental behavior : An integrative agenda. Journal of Environmental Psychology, 29(3), 309-317.

Tapscott, D. (2009). Grown up digital: How the net generation is changing your world. United States: McGraw-Hill.

Weimer, K., Ahlstrom, R., Lisspers, J., \& Lipsanen J. (2017). Values, attitudes, moral judgment competence, locus of control and sense of coherence as determinants of pro-environmental behaviors and behavioral intentions. Journal of Multidisciplinary Engineering Science and Technology (JMEST), 4(5), 2568-2583.

Yang, J. C., Lin, Y. L., \& Liu, Y. (2016). Effect of locus of control on behavioral intention and learning performance of energy knowledge in game-based learning. Journal of Environmental Education Research, 4622, 1-14. https://doi.org/10.1080/13504622.2016.1214865

Yu, T.-Y., \& Yu, T.-K. (2017). The moderating effects of students' personality traits on pro-environmental behavioral intentions in response to climate change. International Journal of Environmental Research and Public Health, 14(12), 1472. doi: https://doi.org/10.3390/ijerph14121472 